\title{
EDITORIAL
}

\section{ARQUIVO ESCOLAR: VIVENCIAR O INUSITADO}

\author{
Maria Cristina Menezes \\ CIVILIS/FE/UNICAMP \\ menezes.mariacristina@gmail.com \\ Maria de Lourdes Pinheiro \\ CIVILIS/FE/UNICAMP \\ pinheiro.lou@gmail.com
}

Com grande satisfação apresentamos a $2^{\mathrm{a}}$ edição da RIDPHE_R, Revista Iberoamericana do Patrimônio Histórico-Educativo. Neste número se inaugura a seção Dossiê, que traz artigos do México, do Chile e de três diferentes regiões do Brasil, Sul, Sudeste e Nordeste.

A proposta desta nova seção, dossiê, está em agregar artigos que se articulam pelas mais diversas formas, por temas, pelos meandros das investigações realizadas, e pelas proposições que discutam dificuldades comuns aos investigadores do patrimônio histórico educativo e que se referem não apenas à conservação e à organização do mesmo, mas também à difusão e possibilidades para a pesquisa.

\section{Dossiê}

O presente Dossiê, intitulado "Patrimônio Histórico-Educativo Escolar: os arquivos históricos em suas instituições de origem", é composto por cinco artigos, dos quais dois projetos que se ocupam em realizar o diagnóstico da situação dos acervos nas instituições, com o objetivo de projetar ações de preservação e organização dos mesmos, em nível nacional, no México e no Chile, visando à futura disponibilização aos investigadores e demais comunidades de interesse. Neste âmbito, os dois artigos estão articulados em interlocução temática nessa seção que se apresenta.

$\mathrm{O}$ artigo dos investigadores mexicanos Siddharta Alberto Camargo e Belinda Arteaga Castillo guarda afinidades com o texto apresentado pelos investigadores chilenos María José Vial Lyon e Rodrigo Esteban Sandoval Díaz. Ambos tratam de projetos, em nível nacional, que têm em comum a preocupação de agregar comunidades de instituições de ensino em prol da recuperação e da organização dos seus acervos históricos, com o propósito 
de intervir nos espaços institucionais visando a preservação dos acervos pertencentes ao patrimonio histórico-educativo escolar. São elucidativos ao divulgarem as dificuldades encontradas no aspecto político, institucional e no das ações necessárias ao desenvolvimento desses projetos. Por outro lado, trazem a importancia do envolvimento não apenas de pesquisadores e técnicos como também das comunidades escolares. Os diagnósticos realizados, tal como no caso mexicano, mostram o quanto as ações preservacionistas ocorrem e se desenvolvem, sobretudo, a partir de iniciativas isoladas pela ação de pesquisadores de universidades como por grupos de docentes e discentes, das próprias instituições, que se desdobram pela preservação dos acervos em seus espaços de origem.

De outra parte, mas ainda no dossiê, o artigo de Eva Maria Siqueira Alves se atém ao trabalho desenvolvido em prol da preservação do arquivo histórico do Atheneu Sergipense, estabelecimento oficial de estudos secundários de Sergipe criado a 24 de outubro de 1870. As ações arroladas, vão ao encontro daquelas apresentadas pelos investigadores do México e Chile, quando uma pesquisadora vai à luta em busca de editais em agências de fomento e organiza uma equipe com bolsistas de várias modalidades de ensino, a partir de sua instituição universitária.

Por sua vez, os artigos das pesquisadoras Alice Rigoni Jacques e Gabriela Mathias de Castro, do Colégio Farroupilha de Porto Alegre, e Katya Zuquim Braghini, Paula Maria de Assis, Ricardo Tomasiello Pedro e Raquel Quirino Piñas, do Colégio Marista arquidiocesano de São Paulo, instigam pela perseverança dos pesquisadores e pela possibilidade aberta em despertar o interesse de instituições de ensino privadas, que guardam acervos valiosos de grande vulto, e a partir da sensibilização de suas comunidades expandirem as rotas de pesquisa, da circulação dos materiais e da divulgação das práticas.

\section{Artigos}

A seção de artigos, por sua vez, não deixa por menos, com 03 trabalhos que se pautam em analisar documentos impressos, manuscritos e objetos tridimensionais que constam em arquivos históricos escolares, como também apresentar 02 propostas de organização de fontes, em diferentes suportes, para as pesquisas em história da educação.

$\mathrm{O}$ artigo "El patrimonio histórico educativo desde el acervo antiguo y los libros de pedagogía en México", de Francisco Hernández Ortiz, traz um importante estudo do autor no Arquivo Histórico da Benemérita e Centenária Escola Normal do Estado de San Luis Potosí, 
com análise dos textos de pedagogia, localizados no antigo acervo da instituição, que eram utilizados pelos estudantes normalistas.

O texto de Silvia Regina Cason, "Um estudo no arquivo histórico documental do $1^{\circ}$ Grupo Escolar de Campinas: rastreando profissões paternas (1928 a 1935)", trata de estudo no supracitado arquivo escolar nos Livros de Matrículas do arquivo histórico da instituição entre 1928 a 1935, em busca de subsídios em outros estudos realizados sobre a temática, para uma compreensão quanto ao pertencimento socioeconômico dos estudantes.

"Modelos de história natural: as imagens dos bustos raciais nos museus escolares", de Felipe Rodrigo Contri Paz, realizado em museus localizados em espaços escolares, na Região Metropolitana de Porto Alegre, articula as imagens representativas dos diferentes tipos raciais humanos, ao verificar e analisar os diferentes usos destes materiais no ensino, com o método intuitivo então em voga no período concernente ao estudo realizado.

Nos estudos que buscaram organizar fontes de investigação, no texto "A produção do inventário da coleção da Prof ${ }^{a}$. Maria Luiza Cardoso sobre a história do ensino militar: perspectivas e desafios", a pesquisadora, que trabalhou mais de 31 anos como militar na área educacional da Força Aérea Brasileira, período suficiente para, ao longo da vida profissional e acadêmica, acumular uma grande variedade de documentos, não somente sobre o ensino na Aeronáutica, mas, também, na Marinha e no Exército, classificados como de arquivo, de biblioteca e museológico, apresenta o processo de constituição e organização da coleção.

"Repositório de Conteúdo Digital: uma biblioteca da história da educação matemática”, de Bruna Lima Ramos, Claudia Regina Boen Frizzarini e Deoclecia de Andrade Trindade, vem para divulgar o armazenamento, preservação, difusão e usos de documentos e materiais relevantes à história da educação matemática, entre o período de 1890 e 1970, em uma biblioteca digital idealizada, produzida e mantida por integrantes do GHEMAT e inserida no projeto "A constituição dos saberes elementares matemáticos: a Aritmética, a Geometria e o Desenho no curso primário em perspectiva histórico-comparativa, 1890-1970” coordenado por Wagner Rodrigues Valente, pesquisador com trabalho reconhecido para além dos estudos em história da educação matemática, devido a importante contribuição que tem trazido à área da história da educação, com interlocução profícua e de longa data.

\section{Documento}


A seção documento traz a experiência vivida no dia a dia do arquivo, na relação direta com os documentos, no trabalho assíduo, árduo, vagaroso em concentração ininterrupta, não poucas vezes a mercê do inusitado. Neste caso, a convivência de bolsistas, pesquisadores de várias modalidades de ensino: Ensino Médio, Graduação, Pós-Graduação, enriquece o diálogo, a busca, a descoberta e o entusiasmo diante do inusitado do arquivo.

\section{Resenha}

As resenhas são necessárias ao entusiasmarem e chamarem a novas leituras. Esta edição apresenta um livro que resultou de importante investigação em um acervo pessoal e que se articula à organização do mesmo. Educação Libertária no Brasil - Acervo João Penteado: Inventário de Fontes, sobre acervo que se encontra reunido no Centro de Memória da Educação (CME) da Faculdade de Educação da Universidade de São Paulo.

- Com os votos de leitura prazerosa e instigante a todos (as), agradecemos o apoio dos autores, demais colaboradores e pareceristas, contribuições fundamentais ao diálogo profícuo e necessário à temática do Patrimônio Histórico-Educativo. 